$\begin{array}{ll} & \text { Etnográfica } \\ \text { etnográfica } & \text { Revista do Centro em Rede de Investigação em }\end{array}$

Antropologia

vol. 19 (1) | 2015

Vol. $19(1)$

\title{
Introdução: Angola na passagem do tempo
}

Introduction: Angola in the passage of time

\section{Jorge Varanda}

\section{Q OpenEdition \\ Journals}

\section{Edição electrónica}

URL: https://journals.openedition.org/etnografica/3931

DOI: 10.4000/etnografica.3931

ISSN: 2182-2891

\section{Editora}

Centro em Rede de Investigação em Antropologia

\section{Edição impressa}

Data de publição: 1 fevereiro 2015

Paginação: 123-138

ISSN: 0873-6561

\section{Refêrencia eletrónica}

Jorge Varanda, «Introdução: Angola na passagem do tempo», Etnográfica [Online], vol. 19 (1) | 2015, posto online no dia 06 março 2015, consultado o 09 fevereiro 2022. URL: http://

journals.openedition.org/etnografica/3931; DOI: https://doi.org/10.4000/etnografica.3931

\section{(c) (i) (9)}

Etnográfica is licensed under a Creative Commons Attribution-NonCommercial 4.0 International License. 


\section{Introdução:}

\section{Angola na passagem do tempo}

\section{Jorge Varanda}

A partir de uma reflexão baseada numa década de idas e vindas ao terreno, literatura secundária e, naturalmente, os textos sobre arte, religião e novas profetizas deste dossiê, pretende-se enfatizar leituras de processos históricos e sociais mais abrangentes. Ao sublinhar alguns aspetos da história e contemporaneidade angolanas e as ligações entre o global e o local, este texto destaca a íntima relação entre períodos históricos aparentemente herméticos (pré-colonial, colonialismo e pós-independência) e a importância de processos sociais, económicos e políticos que perpassam a divisão entre colonial e pós-independência e são fulcrais para o sedimentar de discursos neomodernos sobre Angola.

PALAVRAS-CHAVE: Angola, colonialismo, globalização, arte, igrejas neotradicionais, profetizas.

Introduction: Angola in the passage of time - Considering a decade of intermittent fieldwork, secondary literature and, of course, the scholarship on art, religion and female prophets featured in this issue, this text aims to highlight broader historical and social processes. It examines both historical and contemporary aspects of Angola, as well as global and local relations. In doing so, it underscores the intertwinement between seemingly hermetic historical periods, i.e. pre-colonial, colonial and post-independence, and the importance of social, economic and political processes that permeate the colonial/post-independence divide, and which are central to cement neo-modern discourses and representations about present-day Angola.

KEYWORDS: Angola, colonialism, globalization, art, neo-traditional churches, female prophets.

VARANDA, Jorge (jorge.varanda@gmail.com) - Centro em Rede de Investigação em Antropologia (CRIA), ISCTE - Instituto Universitário de Lisboa (ISCTE-IUL), Portugal; Centro de Malária e Doenças Tropicais (CMDT-LA), Instituto de Higiene e Medicina Tropical, Portugal. 
EM OUTUBRO DE 2004 ATERRAVA NO AEROPORTO 4 DE FEVEREIRO, EM Luanda, para trabalho de campo no âmbito do doutoramento. Nessa altura, Angola estava longe de ser considerada um parceiro comercial apetecível como é hoje.

Quando percorri a cidade a pé o impacto foi imediato: não havia outros ocidentais a andar nas ruas; a cidade estava, como ainda hoje, pejada de carros que ocupavam mais do que as habituais duas faixas de rodagem. Aos famigerados candongueiros ou Hiaces, azuis e brancos, juntavam-se Toyota Corola, que sem caracterização especial se transformavam em táxis. Os carros particulares eram, na sua maioria, veículos 4X4, alguns Humvee ou BMW, Range Rover e os clássicos Land Rover, estes últimos na sua maioria com placa de matrícula verde, sinal de organização não governamental.

As quitandeiras marcavam presença em todas as esquinas e cruzamentos do centro, (re)vendendo mercadorias, medicamentos farmacêuticos, mezinhas tradicionais, bem como produtos frescos, nomeadamente fruta, comes e bebes preparados nos bairros em fogareiros a carvão construídos a partir de jantes de carro. A conjuntura recente de pós-guerra era ainda percetível na cidade. As lojas, prédios, monumentos e até as praias dos restaurantes da ilha eram vigiadas dia e noite por guardas armados com Kalashnikovs. O padrão de urbanização refletia um legado de vários passados: o colonial e o das políticas habitacionais marxistas das décadas de 1980 e 1990, perpetuando-se na contemporaneidade uma cidade dual, dividida entre condomínios fechados e musseques. ${ }^{1}$

Mas nada do que lera previamente me tinha preparado para a visão de centenas de chineses a trabalharem na baixa, particularmente na Mutamba, a (re)construir edifícios governamentais. Era o ano zero dos efeitos práticos do acordo assinado um ano antes entre o governo do MPLA e a China. Esta era uma situação aparentemente paradoxal, tendo em consideração as relações entre estes dois atores durante o conflito civil (Birmingham 2007; Vidal 2007). No entanto, neste processo de globalização, as relações entre os dois agentes históricos não são tão antagónicas como aparentam. Após a independência, depois de apoiar inicialmente a FNLA e depois a UNITA, a China reatou relações diplomáticas e comerciais com o governo do MPLA em 1983 (Sommervile 1989). No entanto, a partir de 2003 a escala relacional modifica-se. O trabalho de terreno na Lunda Norte revelaria que a ação dos novos atores ainda não se sentia nas terras longínquas do Nordeste do país, e por consequência a ressignificação dos expatriados, pelos locais, era restrita. O chamar de uma quitandeira no mercado do Dundo para o meu colega norte-americano - "Soviético, ó soviético! Compra aqui!" - revelava que o status quo nas províncias era ainda reminiscente dos tempos do afro-estalinismo. 
Os resquícios da Guerra Fria e o não pagamento da dívida por parte de Angola ao clube de Paris fizeram com que, pelo menos formalmente, os países ocidentais condicionassem a sua ajuda à implementação de processos democráticos: boa governação, respeito pelos direitos humanos, liberdade de imprensa e melhoria das condições de vida para toda a população. É neste quadro que entram em cena outros atores: China, Brasil e Índia.

$\mathrm{O}$ acordo entre a China e Angola, feito em termos de troca de infraestruturas por matérias-primas, nomeadamente petróleo, criou o que foi definido como o modo angolano de financiamento. ${ }^{2}$ Certo é que, nestes dez anos, Angola mudou. No entanto, como refere um diálogo no filme Il Gattopardo, de Visconti: "If we want things to stay as they are, things will have to change." Mas as mudanças estruturais verificadas têm tido um profundo impacto na sociedade, na economia, na política e na cultura vivenciada.

As estruturas rodoviárias ou ferroviárias, que em 2004 mostravam ainda as "feridas" de dezenas de anos de conflito, pouco têm a ver com as encontradas na década de 2010, fruto do contributo de empresas portuguesas, e também chinesas e brasileiras, estas últimas novos agentes da "globalização subalterna" (Perrot e Malaquais 2009). O mesmo se pode verificar no setor das telecomunicações, onde, mesmo no meio da área do Nambuangongo, na zona dos Dembos, em aldeias remotas, toda a gente sabe que "naquela pedra grande, ao lado da árvore, com o braço um pouco esticado, pode falar". A topografia local integra assim novas interpretações do território.

A indústria da televisão por cabo é um outro sinal da voraz modernidade vivenciada em Angola, sobretudo para os que têm acesso a televisão e a um gerador. As duas empresas angolanas disseminaram a sua utilização para cidadãos comuns, relegando para segundo plano a operadora sul-africana que até aí permitia à elite e aos expatriados um acesso privilegiado à globalização anglo-saxónica.

Mas a falta de uma cadeia de frio faz com que este progresso não se replique com a mesma velocidade no mercado alimentar e na saúde: os grandes supermercados estão concentrados quase exclusivamente nas populosas zonas urbanas costeiras, e há carência de instalações de saúde biomédicas apetrechadas com tecnologia para diagnósticos e terapêutica. Assim, no mundo rural das províncias ainda dominam mercados tradicionais e pequenas lojas com um mínimo de produtos perecíveis, geridas por portugueses, libaneses, chineses, vietnamitas ou alguns angolanos, bem como pequenos hospitais regionais que, com parcos recursos humanos e tecnológicos, competem com "clínicas" tradicionais e igrejas de cura.

2 Para informação detalhada sobre relações macro entre a China e Angola, ver Campos e Vines (2008), Power e Alves (2012). 
É assim sem surpresa que verificamos que, entre 2003 e 2008, Angola apresentou taxas de crescimento de dois dígitos, mantendo-se acima dos 7\% depois disso, verificando-se uma forte melhoria em inúmeros indicadores socioeconómicos. A título de exemplo, entre 1980 e 2012 a esperança de vida à nascença aumentou 11,3 anos e o rendimento nacional bruto per capita aumentou $74 \%$ de 1985 a 2012. Aliás, em Julho de 2012 o Banco Mundial alterou a classificação de Angola de país de lower middle income para país com upper middle income. Apesar destas melhorias, a maior parte da população - 90,9\% - vive com menos de dois dólares norte-americanos por dia (Croese 2012), uma realidade que se reflete na classificação no índice de desenvolvimento, onde o país está na 148. ${ }^{a}$ posição entre 187 territórios analisados (PNUD 2013).

As ondas da modernidade poderiam levar o leitor a pensar que, como no livro de L. P. Hartley, em Angola, “o passado é um país estrangeiro”. No entanto, uma análise mais profunda revela que tal não é tão linear como aparenta. Os artigos deste dossiê levantam o véu sobre a complexidade do trajeto histórico do período colonial no início do século XX à Angola globalizada do presente. Na verdade, questionar se em Angola “o passado é um país estrangeiro" tem de ser considerado como um artifício retórico, uma tentativa de elaborar explicações para um presente aparentemente sem fundações profundas, segundo algumas grelhas de análise. Ora o equívoco não poderia ser maior, pois este sentimento de não pertença relaciona-se mais com discursos e representações de media ou novos atores que "mascaram" a continuidade de diversos processos sociais que trespassam períodos históricos aparentemente estantes.

Alguém que queira compreender a Angola contemporânea tem forçosamente de olhar para além de um único campo do conhecimento, quer seja a antropologia social e cultural, a ciência política, a economia ou a sociologia e, como Chabal e Vidal (2007) tão lucidamente referiram, atentar à história. No entanto, qualquer veleidade de o fazer esbarra com a ausência de uma historiografia sistemática e compreensiva do território pré-colonial, colonial, ou do período após a independência. O objeto de estudo é vasto e complexo.

Partindo de vários estudos de caso sobre arte e religião - incluindo-se nesta última o caráter revolucionário da autoridade carismática tangível na transformação da igreja Tocoísta e na emergência das profetizas de igrejas de cura este dossiê enfatiza as leituras etnográficas e as suas relações com processos sociais mais amplos. Esta introdução realça alguns aspetos da história e da contemporaneidade angolanas, entre dois processos históricos subjacentes - colonialismo e globalização -, e prepara o leitor para um enquadramento conceptual e contextual mais elaborado das etnografias apresentadas neste número da revista Etnográfica.

Pretende-se, assim, evocar a pesquisa de alguns investigadores relacionados com a academia lusófona, que ilustra como, sob um manto de constantes mudanças, processos sociais continuam a moldar a representação do país 
ou, como qualquer antropólogo requereria, permite verificar qual a influência destes processos macro nas biografias das pessoas comuns. De uma chamada ampla foram selecionados três textos que, com maior ou menor grau, obedecem ao principal desiderato do dossiê, ou seja, identificam a relação entre a contemporaneidade e os passados pré-colonial e colonial, ou, como refere o título escolhido para o dossiê que agora se apresenta, entre a vertigem da modernidade e o lastro do passado.

Esta relação é percetível desde a saída do aeroporto internacional de Luanda até à Maianga ou à nova marginal, está presente nos discursos e representações sobre a nova Angola, é visível nas interpretações locais de telenovelas sul-americanas de baixo custo que invadem os bairros periurbanos, ou nas casas de administradores ou dos primeiros-secretários, autênticas casas-"farol" nas noites escuras do mundo rural que recordam o passado.

O trabalho épico de René Pélissier (1997 [1986]), História das Campanhas de Angola: Resistência e Revoltas (1845-1941), revela um século de ações contra os portugueses em diversas áreas do território. Às duas décadas de paz que decorreram do fim das campanhas de pacificação até 1961, ano que marca o início da guerra de libertação, juntam-se agora uma dúzia de anos, de 2002 até a atualidade. São escassos os períodos sem conflitos: diversas revoltas, lutas de libertação ou guerras civis pontuam a história de Angola. Se as produções académicas de cariz antropológico, económicas, de ciência política ou até de saúde pública se cingem à contemporaneidade, enfatizando o presente etnográfico malinowskiano, apesar de poderem enaltecer a "resiliência" do povo, não trazem a lume as raízes dos processos sociais, com mais de século e meio, que sempre exigiram ao povo angolano esforços desumanos para a sobrevivência.

Recorde-se que, no século XIX, Hegel caracterizava os africanos como os selvagens mais selvagens da pirâmide hierárquica racial (Laplantine 1991); estes foram feitos escravos (Miller 1988), foram evangelizados, forçados a trabalhar como mão de obra barata (Ball 2003; Cleveland 2008) e consumidores de mercadorias europeias de baixo custo. Assim, raras foram as alturas em que lhes era dada voz nos arquivos coloniais. A procura da voz das populações locais acontece após a descolonização, com as explorações das primeiras histórias orais (Vansina 1985), ou depois, com as leituras a contrapelo dos estudos subalternos (Guha e Spivak 1998). Daí iniciaram-se outros modos de "ver" os africanos, de tentar ouvir a sua voz num silêncio ensurdecedor de arquivos com quilómetros. No entanto, com ou sem voz, os angolanos e as suas instituições, práticas socioculturais, políticas ou económicas foram e são atores omnipresentes ao longo de décadas de produção académica.

Esta constante luta pela sobrevivência foi e é assim "construída" por via da interpretação académica como resistência ao colonialismo, "fuga" para territórios limítrofes (Van Onselen 1976), resiliência ou relação estratégica com os colonizadores, com o intuito último de manter-se vivo. No entanto, se isto foi 
relatado por Ross (1925) e Galvão (1947) durante o período colonial, após a independência, durante a guerra civil, o mesmo foi replicado entre as populações do planalto central, como nota Florêncio (2010).

Outra dimensão desta continuidade entre contextos históricos verifica-se no papel das igrejas na transformação do tecido social. Em Of Revelation and Revolution, Comaroff e Comaroff (1991) descrevem um processo similar na África do Sul. ${ }^{3}$ Muitas das práticas das congregações religiosas estiveram intimamente relacionadas com a evangelização e as alterações sociais a nível familiar, que eram vistas como parte integrante da missão civilizadora. ${ }^{4}$ No fundo, o desiderato de implementar a missão, no século XIX e início do século XX, traduzia-se na ênfase na descendência patrilinear, nas relações monogâmicas e numa nova atenção prestada ao corpo - o uso de indumentária decente, ou seja, europeia, e cuidados de higiene que surgem com a emergência da medicina tropical (Arnold 1988).

O discurso hegemónico do processo histórico anterior - leia-se a "ação civilizadora" - parece desaparecer com o fim do projeto colonial e consequente debandada de quadros administrativos médios ou superiores, ou diante da perda de relevância de determinados atores. Após a independência, e com maior acutilância desde o final das hostilidades da guerra civil, surge um outro discurso que sublinha o desenvolvimento de uma Angola nova e (neo-) moderna. No entanto, esta Angola da segunda década do século XXI continua a ser o resultado de longos processos históricos que moldam a ação dos inúmeros (novos) atores locais, regionais e internacionais, que renegociam as suas posições, e seguem o mantra da inserção nos trânsitos globais.

A persistência de muitos destes atores sociais em diversos contextos históricos replica-se também em práticas político-administrativas das autoridades tradicionais, que se mantiveram similares ao longo de quase cem anos. ${ }^{5}$ Como em vários outros contextos africanos, as autoridades locais renegociam as suas funções e ações, algo que fizeram durante o período colonial e continuam a efetuar no contexto dos Estados-nação africanos independentes (Neto 2001; Pacheco 2001; Guedes e Lopes 2007; Orre 2007; Florêncio 2010, 2011 ; Oliveira 2013).

Enquanto, no contexto imperial, se conceptualizava que a ação civilizacional levaria à extinção das práticas de feitiçaria, de adivinhação ou dos curandeiros face à força e eficácia da biomedicina, após a independência, o Estado

3 Para o contexto angolano, há várias análises sobre a importância fulcral da religião (cristã e protestante) para melhor compreender as alterações na organização social - veja-se Newitt (1981), Neto (1997), Péclard (1998), Schubert (2000), Messiant (2003) e Florêncio (2010, 2011 ).

4 Sobre a missão civilizadora, ver Alexandre (1999), Ball (2003), Cabecinhas e Cunha (2003) e Henriques (2004).

5 Excetuando, na contemporaneidade, a cobrança de imposto e recrutamento para trabalho forçado. 
e seus representantes continuam a olhar de soslaio para tais práticas, pois vão contra representações e discursos de uma Angola moderna e globalizada.

O 11 de Novembro de 1975 é amiúde associado a uma divisória hermética num (hipotético) conceito de Rorschach colonial, onde a mancha de Rorschach impõe uma separação traduzida num mimetismo do colonial pelo pós-colonial; no entanto, os textos aqui apresentados revelam um quadro menos linear e/ou mimético. Este decalque é relativo.

Angola continua a ser alvo de diversas narrativas, correspondentes a diferentes visões inerentes a diferentes períodos históricos e práticas políticas, de um Estado colonial autorrepresentado como arauto da modernidade ao período após a independência, caracterizado por Tony Hodges (2001) como abrangendo dois momentos diferentes, um Afro-Estalinism e um petro-diamond capitalism. Presentemente, Angola pode ser vista como um Estado em desenvolvimento mas enfaticamente neoliberal. Como Marx escreveu no ano de todas as revoluções europeias, 1848: “Tudo o que é sólido se dissolve no ar". Ou seja, a modernidade angolana não parece ser tão palpável como os discursos da construção de um projeto de Estado hegemónico fazem crer.

Os artigos deste dossiê demonstram a forte relação existente entre o período colonial e o período após a independência, nem que seja para circum-navegar este período histórico. Ou seja, mostram como a História de Angola, e consequentemente o seu presente, estão a ser considerados em termos da mitologia dos movimentos de libertação. A ocupação colonial portuguesa de Angola ganhou relevo nas três décadas iniciais do século XX, ou seja, após a implantação das estruturas do Estado colonial por todo o território (Clarence-Smith 1985), enquanto o processo histórico da globalização, referente ao período após a independência, ganha ímpeto nesta segunda década do novo milénio. As análises presentes nos artigos aqui apresentados realçam as ligações entre o local e o global nos períodos mencionados e a importância de determinados processos sociais, económicos e políticos que perpassam essa divisão entre período colonial e período após a independência, e que são fulcrais para o sedimentar de discursos neomodernos.

O texto de Nuno Porto dá um contributo decisivo para uma melhor compreensão da íntima relação entre arte e poder e da continuidade existente entre os diferentes períodos e processos e novos atores históricos. $\mathrm{O}$ autor traz a lume os fatores políticos e económicos que influenciam a (res)significação e (re)negociação de objetos de arte nas escalas nacionais e globais, no interior de contextos coloniais e após a independência. Os processos culturais (publicações e exposições) dos anos 50-60 do século XX levados a cabo pela Companhia de Diamantes de Angola (Diamang) culminam na criação do conceito da arte Tshokwe. Neste "tempo do colono", a transformação do artefacto em objeto de "arte etnográfica" realizava-se por meio dos etnógrafos enquadrados em instituições "nacionais", como o Museu do Dundo da Diamang. 
Após a independência surgem novos atores sem relação direta a instituições estatais - curadores de feiras de arte internacionais, no caso presente a Trienal de Luanda - que se reapropriam e dão novos significados a artefactos de arte Tshokwe, transformando-a em arte contemporânea.

Nuno Porto, acutilantemente, faz notar que "o fecho formal da situação colonial não implica, necessariamente, o termo de relações coloniais, quer no campo político, quer no campo cultural". O fulcro entre os dois períodos não é passível de se resumir a uma data, pois tal elide os processos de produção da arte entre os contextos em análise. Assim, as reapropriações do século XXI, efetuadas a partir de Luanda, contribuem para o debate sobre a nova identidade nacional de Angola, de assinatura neomoderna e global, relegando a arte etnográfica ou Tshokwe do contexto colonial e centrando-se em (res)significações contemporâneas das artes primeiras que circum-navegam o colonial e vingam em bienais no estrangeiro.

Ao revelarem um pouco sobre a origem e história da Igreja Tocoísta desde a sua génese até ao presente, Blanes e Sarró reforçam a ideia de porosidade entre contextos aparentemente herméticos. Somente em 1992, após a morte de Simão Toco, com políticas de inspiração soviética do MPLA, é que os tocoístas viram a sua igreja legalmente aceite, na última das campanhas de reconhecimento de congregações religiosas. O reconhecimento obriga os tocoístas a confrontarem-se com problemas vários, como as novas problemáticas socioeconómicas, as políticas beligerantes após a independência e a "competição" com as novas igrejas oriundas do espaço transnacional, ligadas aos ramos evangélico, pentecostal e neopentecostal, e, mais importante, com a questão da sucessão carismática face ao desaparecimento do seu profeta.

Em resposta à questão de saber qual é o "verdadeiro tocoísmo" surgem várias correntes dentro da própria congregação. As dinâmicas internas, tangíveis em confrontos geracionais, são reveladoras de um outro confronto vincado na Angola contemporânea. A primazia de uma destas correntes está em sintonia com a narrativa nacional de uma nova Angola com igrejas modernas e em expansão, inseridas em fluxos transnacionais. Blanes e Sarró notam que a imaginação sobre a "realidade" do profeta (quase como simulacro baudrillardiano) e o espalhar da mensagem pelo mundo foram centrais para recuperar o sentimento de presença do profeta entre os novos fiéis na diáspora angolana. Ou seja, neste contexto, o problema da sucessão carismática não se cingiu a um dos modos conceptualizados por Weber, englobando um mecanismo de revelação conjugado com a designação por pessoal qualificado. Subjacente a estes mecanismos de seleção e legitimação do novo líder carismático estava o discurso da modernidade, que incluía ressignificações do(s) passado(s) que contribuiriam para a expansão global da igreja.

O desânimo da Geração Utopia de Pepetela ou a incompletude das políticas governamentais da Angola Jovem são esquecidas face ao "eterno" acreditar no 
progresso, inerente à reinvenção constante de uma narrativa nacional. Este acreditar esteve presente nas mais diversas doutrinas políticas: durante o período colonial era veiculado pela revelação tocoísta para a libertação espiritual dos africanos (Blanes 2014), nas emissões radiofónicas da Angola Combatente, nas produções de música de intervenção do MPLA; no contexto pós-colonial, transforma-se durante os anos afro-estalinistas nas práticas dos "sábados vermelhos”, ou em ações de limpeza de rua ou edifícios; presentemente é palpável na produção comercial musical de semba, kuduro ou hip-hop, ou em produções locais de cinema digital de baixo custo e do-it-yourself, com temáticas de ação ou mensagens religiosas neotradicionais onde a autoridade carismática impera.

Um breve olhar sobre as discussões do Workshop sobre o Fenómeno Religioso em Angola, cujas atas foram publicadas pelo Instituto Nacional para os Assuntos Religiosos (INAR), reforça a perceção da hegemonia da narrativa (neo)moderna em Angola. Enquanto a aceitação do monoteísmo durante o domínio colonial (Caley 2011) é interpretada como "natural" face às semelhanças com a cosmovisão banto, as inúmeras denominações religiosas à espera de reconhecimento por parte do INAR despoletam ansiedade nas outrora seitas que, nas campanhas de 1987 e 1991, obtiveram reconhecimento oficial, "transformando-se" em igrejas (cf. INAR 2011 : 15).

Entende-se que as novas "igrejas hóspedes" desvirtuam os valores culturais angolanos, pois "promovem a prática de acusação de crianças e idosos feiticeiros [...] aproveitando-se das condições de vida das pessoas, retiram-lhes o pouco que têm, prometendo-lhes mundos e fundos, prometem emprego, casamentos, curas" (Luvualo 2011), ou então por só apresentarem templos e falharem na apresentação de hospitais, colégios, universidades ou instituições de teologia (Caley 2011: 27). Estas são conceptualizações intimamente relacionadas com as missões cristãs ou protestantes do contexto colonial.

$\mathrm{O}$ "tradicional", ou passado pré-colonial, apresenta um manancial de possibilidades. $\mathrm{O}$ académico angolano Caley refere que só um olhar científico e o mapeamento das práticas religiosas da situação antecolonial permitem conhecer melhor "o homem africano" (Caley 2011: 27). De acordo com esta visão, argumenta-se pela criação de um sistema de capacitação, qualificação e controlo permanente dos líderes religiosos no domínio teológico e outras formações científicas (Sebastião 2011). Estas ideias enfatizam a relação entre Estado e Igreja existente desde o período colonial, mas agora passível de ser reinterpretada de forma mais abrangente com elementos discursivos que referem que "O Estado é o Deus na Terra" (Malanda 2011).

A apropriação do repositório tradicional é efetuada seletivamente e com o intuito de ter uma visão clara do progresso - por exemplo, quando os fiéis, face a dificuldades provocadas pela economia de mercado, evocam antigos reis da resistência colonial como Ngola Kiluange, Njinga Bandi, Ekuikui, Mandume, Nunduma (Caley 2011). Esta reapropriação do passado, através do culto de 
profetas realizado por meio de atos performativos, como Viegas e Varanda notam, cria espaço para as novas profetizas que negociam novos papéis de género num contexto marcado pela hegemonia patriarcal. ${ }^{6}$ No entanto, há que evitar cair em exotizações fáceis na análise das ressignificações referentes ao passado colonial e pré-colonial ou "tradicional", pois nas sociedades ocidentais também existem heróis míticos e acontecimentos fundacionais que, podendo ser historicamente verídicos ou não, são sustentados por uma rede de significados (Kertzer 1998: 12-13).

As lentes da religião, tais como as da arte, são importantes para entender os processos de (re)construção do discurso da nação, um discurso que valoriza as qualidades construídas, "atribuídas" à Angola moderna, por sua vez integrada em fluxos globais e onde a ciência é um dos arautos do progresso, inclusive no campo religioso.

Viegas e Varanda centram-se nas igrejas neotradicionais da Luanda do início do século XXI e mostram como os discursos de uma Angola moderna, tecnológica e científica, por vezes, não são verificados no terreno. A juntar à provisão de conforto espiritual, de sentimento de pertença a uma comunidade, como refere Durkheim, a década de 1990 trouxe uma transformação simbólica das igrejas, verificando-se uma apropriação de novas competências, como a capacidade de cura e a abertura de um espaço societal que possibilita a ressignificação de biografias femininas e a negociação de papéis de género.

O discurso das várias igrejas nasce no seio de uma representação vincada da modernidade angolana. As dicotomias indivíduo/comunidade e tradicional/moderno constituem as bases para a construção de uma identidade própria das igrejas neotradicionais, com cultos que incluem sessões de possessão, ritos de exorcismo e cura, conduzidos de acordo com novas interpretações bíblicas que enfatizam a resiliência da população para vencer as dificuldades quotidianas. Os carismas atribuídos às profetizas mostram o seu caráter revolucionário, ao permitirem que estas mulheres deem novos significados às suas biografias e, ao mesmo tempo, criem novos percursos sociais, bem como espaços de esperança para as suas discípulas.

As "incumbências" autorreclamadas pelas igrejas neotradicionais copiam as práticas das igrejas históricas do contexto colonial, atenuando os problemas vivenciados pelas pessoas e, em alguns casos, substituindo o Estado no cumprimento dos deveres sociais. Este último apontamento é um dos fenómenos centrais no projeto da Angola contemporânea - a manutenção do papel central das igrejas, tal como tiveram no passado, para a sobrevivência de milhões de angolanos. Como notou Durkheim, não há religiões falsas, pois a função da religião é ajudar a viver melhor; todas elas respondem, de forma diferente, às condições da existência humana. 
O contexto da macroficção da modernidade onde o Estado-nação impera força mais uma vez à continuidade, neste caso nos processos de construção simbólica. Até aos anos 50, as missões religiosas (católicas e protestantes) substituíam o Estado na prestação de cuidados biomédicos, nomeadamente nas zonas rurais (Ross 1925; Galvão 1947). Outros elementos centrais para o projeto colonial eram as empresas coloniais que dominavam largas áreas do território, como a Companhia de Diamantes de Angola (Diamang), ou os Caminhos de Ferro de Benguela e Cassequel, que também atuavam no âmbito sanitário com programas de saúde pública próprios (Varanda 2014). ${ }^{7}$ No contexto após a independência, a par de programas verticais como as ações das equipas móveis contra a doença do sono e para a erradicação da poliomielite, que representam o Estado em áreas fora dos centros urbanos costeiros e/ou provinciais, estas igrejas de cura devem também ser consideradas como atores relevantes em contextos do interior.

Ao aceitar-se o pressuposto de que as entidades políticas são construções simbólicas resultantes de um processo longo e complexo de construção de uma identidade nacional, onde diferentes indivíduos se reveem na entidade abstrata que é a nação (Kertzer 1998), deve ter-se em conta o papel dos novos atores neotradicionais nesse processo. Este esforço de construção simbólica de uma nação é facilitado com recurso a heróis fundacionais que tenham resistido aos avanços coloniais (Ngola Kiluange, Njinga Bandi, Ekuikui, Mandume, Nunduma), a heróis que tenham libertado o povo do jugo imperial (Agostinho Neto), ou, no contexto contemporâneo, que tenham conseguido a paz e mantido a unidade nacional e/ou territorial (José Eduardo do Santos) face a "inimigos” internos. Há que ir além e considerar as próprias instituições estatais como fazedoras de simbologias da nação. Tal reflete-se nos edifícios dos governos provinciais, municipais ou comunais, bem como nos coordenadores de bairros presentes nas cidades ou pequenas vilas ou aldeias, mas também em instituições educacionais ou de saúde.

Messiant (1999, 2007), Jensen e Pestana (2010), e Oliveira (2013) referem que, paralelamente a esta construção simbólica, decorre o processo de relegar algumas das funções do Estado para a sociedade civil. Enquanto a falecida autora francesa revela a inter-relação entre organizações não governamentais e figuras governamentais (Messiant 1999, 2007), Jensen e Pestana (2010) apontam a centralidade das igrejas para matizar as condições de "violência estrutural", como nota o conceito de Farmer (1999), em que a maioria dos angolanos se encontra. Oliveira (2013) refere a crescente colagem entre o Estado-nação e o Estado-partido e a importância de alguns atores locais neste processo.

7 Para um estudo de caso sobre Caminhos de Ferro de Benguela (CFB) e Sociedade Agrícola do Cassequel, ver Esteves (1999) e Ball (2003). Para o caso da Diamang, ver Varanda (2007), Cleveland (2008) e Porto (2010). 
Estes imaginários de outra globalização por vezes confrontam-se com o imaginário dominante da globalização do Norte. São raras as notícias sobre a Angola contemporânea que não incidam na sua dimensão económico-financeira. A economia do processo de globalização pode ser avassaladora, mas é imperioso considerar as perceções e histórias, as biografias dos novos atores, suas trajetórias e práticas, processos de (re)construção de identidade, projetos culturais ou económicos da elite, bem como os olhares estatais - em resumo, é necessário atentar às lógicas locais e regionais, integrando-as em processos histórico-sociais inerentes (neste caso, a globalização), pois viver e/ou negociar em Angola implica lidar com inúmeras idiossincrasias. Só assim se poderá compreender melhor Angola no início do século XXI.

Em Angola, a mudança constante, reflexo da história e progresso da ciência e da técnica, é parte inerente da modernidade. Mas como refere o filósofo inglês John Gray, a crença contemporânea no progresso é, paradoxalmente, quase religiosa. ${ }^{8}$ Há um sentimento inabalável de que o avanço no conhecimento e na tecnologia terá paralelo em progressos socioculturais, éticos e políticos. Ou seja, acredita-se que este movimento transformador trará benefícios num devir próximo, que os descendentes imediatos viverão melhor. No entanto, avisa Gray, esta é uma crença que, para a maioria das pessoas, não se concretizará. Esta conceção cega a compreensão do movimento lento das rodas da engrenagem da história e da sua tradução no real, visão que é ilustrada nos três textos deste dossiê.

Mas a voracidade da mudança socioecónomica descrita nestas páginas de um modo geral reflete-se também nas fraturas classificatórias de que os expatriados são objeto por parte dos locais. Se, por exemplo, voltasse ao mesmo mercado do Dundo com o colega norte-americano, este já não seria classificado como "soviético" pelas quitandeiras. O roulement de atores verificado entre 1980 e 2014 impeliria a uma ressignificação do expatriado, já não chamado "branco"; seguiriam antes o exemplo das crianças das aldeias nas áreas rurais das províncias do Bengo, Kwanza Sul e Uíge, que nos últimos anos, quando me viam, chamavam: "Ó chinês, ó chinês!" 


\section{BIBLIOGRAFIA}

ALEXANDRE, Valentim, 1999, "O Império e a ideia de raça (séculos XIX e XX)", em Jorge Vala (org.), Novos Racismos: Perspectivas Comparativas. Oeiras, Celta Editora, 133-144.

ARNOLD, David, 1988, "Introduction”, em David Arnold (org.), Imperial Medicine and Indigenous Societies. Manchester, Manchester University Press, 1-26.

BALL, Jeremy, 2003, "The Colossal Lie": The Sociedade Agrícola do Cassequel and Portuguese Colonial Labor Policy in Angola, 1899-1977. Los Angeles, University of California, tese de doutoramento.

BIRMINGHAM, David, 2007, "Angola”, em Patrick Chabal et al., A History of Postcolonial Lusophone Africa. Bloomington, Indiana University Press, 139-184.

BLANES, Ruy Llera, 2014, A Prophetic Trajectory: Ideologies of Place, Time and Belonging in an Angolan Religious Movement. Nova Iorque, Berghahn Books.

BUTLER, Judith, 1998, "Performative acts and gender constitution: An essay in phenomenology and feminist theory", Theatre Journal, 40 (4): 519-531.

CABECINHAS, Rosa, e Luís CUNHA, 2003, "Colonialismo, identidade nacional e representações do "negro"”, Estudos do Século XX, 3: 157-184.

CALEY, Cornélio, 2011 , "As religiões tradicionais africanas e universais em Angola em tempos de renascença", em Actas do Workshop sobre o Fenómeno Religioso em Angola: Um Debate Recorrente (Luanda, 14 e 15 de Junho). Luanda, Instituto Nacional para os Assuntos Religiosos, Ministério da Cultura, 19-28.

CAMPOS, Indira, e Alex VINES, 2008, "Angola and China: A pragmatic partnership", apresentado na conferência "Prospects for Improving US-China-Africa Cooperation" (Center for Strategic and Internacional Studies, Londres, Chatham House, 5 de dezembro de 2007), disponível em < http://csis.org/files/media/csis/pubs/080306_angolachina.pdf > (última consulta em janeiro de 2015).

CHABAL, Patrick, e Nuno VIDAL (orgs.), 2007, Angola: The Weight of History. Londres e Nova Iorque, Hurst \& Columbia University Press.

CLARENCE-SMITH, Gervaise, 1985, The Third Portuguese Empire: 1825-1975. Manchester, Manchester University Press.

CLEVELAND, Todd, 2008, Rock Solid: African Laborers on the Diamond Mines of the Companhia de Diamantes de Angola (Diamang), 1917-1975. Minneapolis, University of Minnesota, tese de doutoramento.

COMAROFF, Jean, e John COMAROFF, 1991, Of Revelation and Revolution, vol. 1: Christianity, Colonialism, and Consciousness in South Africa, Chicago, The University of Chicago Press.

CROESE, Sylvia, 2012, "One million houses? Chinese engagement in Angola's national reconstruction”, em Marcus Power e Ana Cristina Alves (orgs.), China and Angola: A Marriage of Convenience?. Oxford, Pambazuka Press, 124-138.

ESTEVES, Emmanuel, 1999, O Caminho de Ferro de Benguela e o Impacto Econômico, Social e Cultural na Sua Zona de Influência, 1902-1952. Porto, Universidade do Porto, tese de doutoramento.

FARMER, Paul, 1999, Infections and Inequalities: The Modern Plagues. Berkeley, Los Angeles e Londres, University of California Press.

FLORÊNCIO, Fernando, 2010, “No reino da toupeira: autoridades tradicionais do M'Balundu e o Estado angolano", em Fernando Florêncio et al., Vozes do Universo Rural: Reescrevendo o Estado em África. Lisboa, Centro de Estudos Africanos/ISCTE-IUL e Gerpress, 79-175. 
FLORÊNCIO, Fernando, 2011 , "Pluralismo jurídico e Estado local em Angola: Um olhar crítico a partir do estudo de caso do Bailundo", Antropologia Portuguesa, 28: 95-134.

GALVÃO, Henrique, 1947, "Exposição do deputado Henrique Galvão, Comissão de Colónias da Assembleia Nacional, em Janeiro de 1947”. Lisboa, Arquivo Histórico-Parlamentar, Assembleia da República, manuscrito.

GRAY, John, 2002, Straw Dogs: Thoughts on Humans and Other Animals. Londres, Granta Books.

GRAY, John, 2004, Heresies: Against Progress and Other Illusions. Londres, Granta Books.

GRAY, John, 2007, Black Mass: Apocalyptic Religion and the Death of Utopia. Londres, Penguin Books.

GUEDES, Armando Marques, e Maria José LOPES (orgs.), 2007, State and Traditional Law in Angola and Mozambique. Coimbra, Almedina.

GUHA, Ranajit, e Gayatri Chakravorty SPIVAK (orgs.), 1998, Selected Subaltern Studies. Oxford, Oxford University Press.

Henriques, Isabel Castro, 2004, Os Pilares da Diferença: Relações Portugal-África, Séculos $X V$-XX. Casal de Cambra, Caleidoscópio Edição.

HODGES, Tony, 2001, Angola: From Afro-Stalinism to Petro-Diamond Capitalism. Oxford, James Currey.

INAR, 2011, Actas do Workshop sobre o Fenómeno Religioso em Angola: Um Debate Recorrente (Luanda, 14 e 15 de Junho). Luanda, Instituto Nacional para os Assuntos Religiosos, Ministério da Cultura.

JENSEN, Søren Kirk, e Nelson PESTANA, 2010, O Papel das Igrejas na Redução da Pobreza em Angola. Bergen, CHR Michelsen Institute.

KertZer, David I., 1998, Ritual, Politics and Power. New Haven, Yale University Press.

LAPLANTINE, François, 1991, Aprender Antropologia. São Paulo, Editora Brasiliense.

LUVUAlO, Paulo, 2011, "Igreja de Nosso Senhor Jesus Cristo no Mundo", em Actas do Workshop sobre o Fenómeno Religioso em Angola: Um Debate Recorrente (Luanda, 14 e 15 de Junho). Luanda, Instituto Nacional para os Assuntos Religiosos, Ministério da Cultura, 117-118.

MALANDA, Felipe, 2011 , "Igreja da Mensagem do Último Templo", em Actas do Workshop sobre o Fenómeno Religioso em Angola: Um Debate Recorrente (Luanda, 14 e 15 de Junho). Luanda, Instituto Nacional para os Assuntos Religiosos, Ministério da Cultura, 120.

MESSIANT, Christine, 1999, "La Fondation Eduardo dos Santos (FESA): a propos de 'l'investissement' de la société civile par le pouvoir angolais”, Politique Afrique, 73: 82-102.

MESSIANT, Christine, 2003, "Les Eglises et la dernière guerre en Angola: Les voies difficiles de l'engagement pour une paix juste”, Social Sciences \& Missions, 13: 75-11.

MESSIANT, Christine, 2007, "The mutation of hegemonic domination: multiparty politics without democracy”, em Patrick Chabal e Nuno Vidal (orgs.), Angola: The Weight of History. Londres e Nova Iorque, Hurst \& Columbia University Press, 93-123.

MILLER, Joseph C., 1988, Way of Death: Merchant Capitalism and the Angolan Slave Trade, 1730-1830. Londres, James Currey.

NETO, Maria Conceição, 1997, "Entre a tradição e a modernidade: os Ovibundo do planalto central à luz da história”, Ngola: Revista de Estudos Sociais, 1: 193-215.

NETO, Maria Conceição, 2001, "Angola: the historical context for reconstruction", em Paul Robson (org.), Communities and Reconstruction in Angola. Luanda, Development Workshop, 23-49. 
NEWITT, Malyn, 1981, Portugal in Africa: The Last Hundred Years. Londres, Hurst e Co.

OLIVEIRA, Ricardo Soares de, 2013, “'O governo está aqui': postwar State-making in the Angolan periphery”, Politique Africaine, 130: 165-187.

ORRE, Aslak Jangård, 2007, "Integration of traditional authorities in local governance in Mozambique and Angola: The context of decentralization and democratisation", em Armando Marques e Maria José Lopes (orgs.), State and Traditional Law in Angola and Mozambique. Coimbra, Almedina, 139-199.

PACHECO, Fernando, 2001, "Rural communities in Huambo", em Paul Robson (org.), Communities and Reconstruction in Angola. Luanda, Development Workshop, 151-173.

PÉCLARD, Didier, 1998, "Religion and politics in Angola: The Church, the colonial State and the emergence of Angolan nationalism (1940-1961)", Journal of Religion in Africa, 28 (2): 160-186.

PÉLISSIER, René, 1997 [1986], História das Campanhas de Angola: Resistência e Revoltas, 1845-1941. Lisboa, Editorial Estampa, 2 vols.

PERROT, Sandrine, e Dominique MALAQUAIS, 2009, "Penser l'Afrique à l'aune des globalisations emergentes", Politique Afrique, 113: 5-27.

PNUD, 2013, A Ascensão do Sul: Progresso Humano Num Mundo Diversificado (Resumo do Relatório do Desenvolvimento Humano 2013). Washington, DC, Programa das Nações Unidas para o Desenvolvimento, disponível em < http://hdr.undp.org/sites/default/files/hdr13 summary_pt_web.pdf $>$ (última consulta em janeiro de 2015).

PORTO, Nuno, 2010, Modos de Objectificação da Dominação Colonial: O Caso do Museu do Dundo, 1940-1970. Lisboa, Fundação Calouste Gulbenkian e FCT/MCTES.

POWER, Marcus, e Ana Cristina ALVES, 2012, China and Angola: A Marriage of Convenience?. Oxford, Pambazuka Press.

ROBSON, Paul, 2001, "Communities and community institutions in Luanda", em Paul Robson (org.), Communities and Reconstruction in Angola. Luanda, Development Workshop, 163-181.

ROSS, Edward Alsworth, 1925, Report on the Employment of Native Labor in Portuguese Africa. Nova Iorque, The Abbott Press.

SCHUBERT, Benedict, 2000, A Guerra e as Igrejas: Angola, 1961-1991. Basel, P. Schlettwein Publishing.

SEBASTIÃO, Kanasidibo Aleluya, 2011, "Santa Igreja Cristã Apostólica Almo Consagrado em Angola”, em Actas do Workshop sobre o Fenómeno Religioso em Angola: Um Debate Recorrente (Luanda, 14 e 15 de Junho). Luanda, Instituto Nacional para os Assuntos Religiosos, Ministério da Cultura, 119.

SOMmerVILlE, Keith, 1989, Angola: Politics, Economics and Society. Londres, Pinter Publishers.

VAN ONSELEN, Charles, 1976, African Mine Labor in Southern Rhodesia, 1900-1933. Joanesburgo, Ravan Press.

VANSINA, Jan, 1985, Oral Tradition as History. Madison, The University of Wisconsin Press.

VARANDA, Jorge, 2007, "A Bem da Nação": Medical Science in a Diamond Company in Twentieth-Century Colonial Angola. Londres, University College London, tese de doutoramento.

VARANDA, Jorge, 2014, "Cuidados biomédicos de saúde em Angola e na Diamang, das décadas de 1910 a 1970”, História, Ciências, Saúde: Manguinhos, 21 (2): 587-608. 
VIDAL, Nuno, 2007, “The Angolan regime and the move to multiparty politics”, em Patrick Chabal, e Nuno Vidal (orgs.), Angola: The Weight of History. Londres e Nova Iorque, Hurst \& Columbia University Press, 124-174.

VIEGAS, Sílvia Leiria, 2012, "Urbanization in Luanda: Geopolitical framework, a socio-territorial analysis, em Proceedings of $15^{\text {th }}$ International Planning History Society Conference, disponível em <http://www.fau.usp.br/15-iphs-conference-sao-paulo-2012/abstractsAnd PapersFiles/Sessions/29/VIEGAS.pdf > (última consulta em janeiro de 2015). 